\title{
The Sexual Concerns of African American, Asian American, and White Women Seeking Routine Gynecological Care
}

\author{
MAJ Margaret R. Nusbaum, MC, USA, Loretta Braxton, PhD, and \\ Gregory Strayborn, $M D, P b D$
}

Purpose: Because of limited knowledge regarding the sexual health of minority women, we described the types and frequency of sexual concerns among African American, Asian American, and white women.

Methods: The sexual concerns of eligible women who received their health care at a large military health care facility in Washington State were determined from December 1992 through January 1993 through the use of a questionnaire on women's sexual health that was developed by one of the authors.

Results: A high and similar prevalence of sexual concerns was reported among these women. The prevalence of certain sexual concerns among white, African American, and Asian American women differed significantly. A history of sexual coercion or physical/emotional abuse was strongly associated with a high prevalence of sexual concerns for each racial and ethnic group.

Conclusion: Although women of different racial/ethnic backgrounds reported a high and similar prevalence of sexual concerns, there were significant differences in the prevalence of certain sexual concerns that may have differential health importance. Health-care providers should exercise caution when generalizing the sexual concerns of women from different racial/ethnic backgrounds. (J Am Board Fam Pract 2005;18:173-9.)

Sexuality plays an integral role in health, quality of life, and general well-being. For women, the risk of unwanted pregnancy, sexually transmitted diseases, and sexual exploitation are threats to their sexual health. Family physicians must consider women's sexual concerns to provide comprehensive health services. In addition, family physicians must consider the variation in sexual concerns that may exist among different racial and ethnic groups of women.

Nusbaum et $\mathrm{al}^{1}$ found a high prevalence of sexual concerns among women seeking routine gynecological care at 2 outpatient military clinics including lack of interest in sex, difficulty with

Submitted, revised, 21 February 2005.

From the Madigan Army Medical Center, Tacoma, WA (MRN), Veterans Affairs Hospital, Durham, NC (LB), and Department of Family Medicine, Morehouse School of Medicine, Atlanta, GÁ (GS). Address correspondence to Gregory Strayhorn, MD, PhD, 805 Peachtree Street \#105, Atlanta, GA 30308 (e-mail: strayhrn@bellsouth.net).

* Current address: Department of Family Medicine, University of North Carolina, School of Medicine, Chapel Hill, NC.

This work was presented at the North American Primary Care Research Group Annual Conference, 2003 Oct 25-28; Banff, Canada.

None of the authors has any conflict of interest related to this research. orgasm, inadequate lubrication, dyspareunia, body image concerns, unmet sexual needs, the need for information about sexual issues, physical and sexual abuse, and sexual coercion. However, this study did not explore possible differences in sexual concern across racial and/or ethnic groups. We found only one study, by Laumann, ${ }^{2}$ that compared self-reported sexual dysfunction of a national probability sample of white, African American, Hispanic, and another category of women. Of the 5 reported categories of sexual dysfunction, compared with white women, African American and Hispanic American women were significantly less likely to report trouble with lubrication during intercourse. However, the limited categories of sexual concerns fails to provide a more comprehensive understanding of the sexual concerns of women from different racial and ethnic backgrounds.

Based on limited knowledge of the diversity of sexual concerns among women of different racial/ ethnic backgrounds, physicians may generalize the sexual concerns of one group to all women thus providing suboptimal sexual health care. To address the limited knowledge and variation of sexual concerns among racial and ethnically diverse women, this study identified the types and preva- 
lence of sexual concerns among African American, Asian American, and white women. The prevalence of African American and Asian American sexual concerns was compared with that of white women. In additional statistical analyses, we determined demographic predictors of having a high number of sexual concerns for each of the 3 racial/ethnic groups.

\section{Methods}

Our sample consisted of women who sought their routine gynecological care at the Departments of Family Medicine and Obstetrics and Gynecology of the Madigan Army Medical Center, a large military medical center located in Pierce County, Washington. Women who were 18 years of age or older, active duty service members, active military reserve, retired military members, their families, employed or retired civilian service members, and beneficiaries of members were eligible to participate. Women were excluded if they were younger than 18 years, were unable to understand English, were geographically unavailable for follow-up, or had cognitive dysfunctions that prevented them from completing the questionnaire. After the selfadministered survey was mailed, a reminder postcard was sent 3 weeks later to nonrespondents. After excluding respondents whose surveys were returned because of invalid mailing addresses, who had died, who were unable to speak English, or whose family member or physician deemed them cognitively dysfunctional, 1480 women were eligible to participate.

The questionnaire consisted of 95 questions seeking sociodemographic characteristics, aspects of patients' sexual history, sources of knowledge about sex, their sexual concerns, and their interest and experience with addressing these concerns with physicians. The 26 types of sexual concern questions were drawn from one author's clinical experience of providing health care to a large and diverse female population at this medical center and a review of the sexuality literature. Responses were measured on a 5 -point Likert scale $(1=$ never; $5=$ always). The development of the questionnaire included: field testing on Red Cross volunteers who were typically 60 years or older, female physician colleagues and female spouses of male colleagues, formal pilot testing on 100 women from the same study population but who did not participate in the study, and content validity review by a women's health research expert and psychologist specializing in the sexual issues of women. For this study, the Cronbach $\alpha$ reliability coefficient for the 26-item sexual concerns section of the questionnaire was 0.85 and was similar for each racial/ethnic group.

The $\chi^{2}$ statistic was used to compare the nominal and ordinal demographic characteristics of racial/ethnic groups. The one-way analysis of variance was used to compare the mean ages of the racial/ethnic groups.

A response of "always to occasional" for each sexual concern was recoded "yes," and never, "no." To determine the prevalence of each sexual concern within each racial/ethnic group, we calculated the proportion of respondents who responded "yes." By tradition, white persons are used as the referent group when exploring differences in health indices among racial and ethnic groups; thus, the specific sexual concerns of African American and Asian American women were compared with those of white women. Logistic regression was used to compute prevalence odds ratios to compare African American and Asian American women's sexual concerns with those of white women. In the regression analysis, we controlled for age, education, religion, income, marital status, and employment. Given the exploratory nature of this study a $P$ value less than or equal to .1 was considered statistically significant.

To compare the relative importance of sexual concerns (based on their prevalence) across groups, we ranked the prevalence of sexual concerns for each racial/ethnic group from highest to lowest. The Kruskal Willis test was used to determine whether the relative ranking of sexual concerns based on their prevalence was similar across groups.

Perceptions of sexual concerns can be influenced by socioeconomic status, religious preferences, age, and marital status, and we sought to explore the association between these demographic characteristics and women's perceived sexual concerns. Given the limited sample size of our African American and Asian American participants, the study had limited power to find statistical significant associations between sexual concerns and demographic characteristics. To address this limitation, we chose to divide each racial/ethnic group into women who reported high levels of sexual concerns and women who reported low levels by first adding the "yes" responses to determine the total number of sexual 
concerns per respondent and using the median split to create high and low sexual concern groups. Logistic regression was used to determine the demographic predictors of a high number of sexual concerns for the overall cohort and for each racial group. Because there is a known association between sexual dysfunction and a history of emotional/physical abuse or sexual coercion, these forms of sexual concerns were removed from the calculation of the total number of sexual concerns. Their potential effect was controlled in separate logistic regression models when determining the demographic predictors of having a high level of sexual concerns. Emotional/physical abuse referred to nonsexual abuse whereas sexual coercion referred to forced sexual activity. Thus, separate regression models were determined for each of these forms of abuse. SPSS (ver 10; SPSS Inc., Chicago, IL) was used for all analyses.

\section{Results}

Completed questionnaires were received from 964 of the 1480 eligible women, a $65 \%$ response rate. For the purposes of these analyses, we used responses from 881 participants; 66 responses were from African American women, 111 responses were from Asian American women, and 704 responses were from white women. Responses from other racial/ethnic groups that made up the remainder of the 964 respondents were too few to make meaningful comparisons.

\section{Demographic Characteristics}

African American women were significantly more likely to be employed and were younger than Asian American and white women. Compared with African and Asian American women, white women were significantly more likely to have some college education, whereas Asian American women were significantly more likely to have at most completed high school. The vast majority of women were married. White women were significantly more likely to have incomes of more than $\$ 40,000$. Asian American women were more likely to have incomes of $\$ 25,000$ or less, and African American women were more likely to have incomes between $\$ 25,000$ and \$40,000. Asian American and African American women were more likely to report "no religious conviction" (Table 1).

\section{Prevalence of Sexual Concerns and Comparison of Sexual Concerns of White Women with African American and Asian American Women.}

More than 50\% of African American, Asian American, and white women reported one or more sexual concerns. The relative prevalence of sexual concerns across the 3 groups did not statistically differ $\left(\chi^{2}=0.375, d f=2, P=.829\right)$ (Table 2).

Compared with white women, African American women were statistically less likely to report concerns regarding vaginal lubrication and lack of sex appeal. African American women were statistically more likely to report concerns about HIV/AIDS, safe sex/sexually transmitted diseases, thinking too much about sex, and a desire to have or having had an affair (Table 2).

Compared with white women, Asian American women were statistically less likely to report concerns related to a lack of interest in sex, difficulty having orgasms, lack of sex appeal, inability to have orgasms, unsatisfied sexual needs, partner sexual concerns, or childhood emotional/physical abuse. Asian American women were significantly more likely to report concerns about HIV/AIDS, difficulty with penile penetration, safe sex/sexually transmitted diseases, sexual aversion, sexual orientation, and sexual abuse toward others (Table 2).

\section{Relationship of Demographic Characteristics with High Number of Sexual Concerns}

We explored associations between a high number of sexual concerns (higher than the median for each racial/ethnic group) and the women's demographic characteristics. The median numbers of total sexual concerns reported by Asian American, African American, and white women were 12 (range, 0 to 26), 13.5 (range, 0 to 23), and 13 (range, 0 to 26), respectively. These values were reasonably distributed and did not cluster around the median. Compared with white women, fewer African and Asian American women reported a high number of sexual concerns. Younger women among the $3 \mathrm{racial} / \mathrm{eth}-$ nic groups were more likely to report a high number of sexual concerns. Married women across each racial group reported a higher number of sexual concerns than those who were widowed or single. This was most pronounced among young African American women. Asian and African American women with no religious convictions were more likely to report a high number of sexual concerns, whereas white women with strong religious convic- 
Table 1. Comparison of Demographic Characteristics among White, African American, and Asian American Women

\begin{tabular}{|c|c|c|c|}
\hline Characteristics & $\begin{array}{c}\text { White Women } \\
\%(\mathrm{~N})\end{array}$ & $\begin{array}{c}\text { African American Women } \\
\%(\mathrm{~N})\end{array}$ & $\begin{array}{c}\text { Asian American Women } \\
\%(\mathrm{~N})\end{array}$ \\
\hline \multicolumn{4}{|l|}{ Employment Status } \\
\hline Outside of home & $39(276)$ & $58(38)$ & $41(45)$ \\
\hline Homemaker & $33(234)$ & $30(20)$ & $13(14)$ \\
\hline Homemaker and childcare & $12(86)$ & $8(5)$ & $43(48)$ \\
\hline Other & $15(105)$ & $5(3)$ & $4(4)$ \\
\hline Missing data & $0.5(3)$ & & \\
\hline \multicolumn{4}{|l|}{ Education } \\
\hline$\leq$ Some high school & $7(47)$ & $11(7)$ & $21(23)$ \\
\hline Completed high school & $30(208)$ & $36(24)$ & $41(37)$ \\
\hline Some college & $40(281)$ & $30(20)$ & $29(32)$ \\
\hline$\geq$ College degree & $23(164)$ & $23(15)$ & $14(15)$ \\
\hline Missing data & $1(4)$ & & \\
\hline \multicolumn{4}{|l|}{ Relationship } \\
\hline Married & $86(603)$ & $86(56)$ & $83(92)$ \\
\hline Widowed & $6(42)$ & $3(2)$ & $15(17)$ \\
\hline Living together & $3(18)$ & & $1(1)$ \\
\hline Single/never married & $2(17)$ & $2(1)$ & $1(1)$ \\
\hline Single/divorced & $2(14)$ & $2(1)$ & \\
\hline Other & $1(10)$ & $8(5)$ & \\
\hline Missing data & & $2(1)$ & \\
\hline \multicolumn{4}{|l|}{ Income } \\
\hline$\leq \$ 25,000$ & 34 (239) & $35(23)$ & $41(45)$ \\
\hline$>\$ 25,000$ to $\$ 40,000$ & $33(233)$ & $41(27)$ & $36(40)$ \\
\hline$>\$ 40,000$ to $\$ 55,000$ & $17(116)$ & $14(9)$ & $12(13)$ \\
\hline$>\$ 55,000$ to $\$ 70,000$ & $8(59)$ & $3(2)$ & $2(2)$ \\
\hline$\geq \$ 70,000$ & $5(34)$ & $2(1)$ & $2(2)$ \\
\hline Missing & $3(23)$ & $6(4)$ & $8(9)$ \\
\hline \multicolumn{4}{|l|}{ Religious Conviction } \\
\hline Very strong & $18(124)$ & $8(5)$ & $21(23)$ \\
\hline Strong & $19(130)$ & $16(10)$ & $12(13)$ \\
\hline Somewhat strong & $25(175)$ & $23(14)$ & $20(22)$ \\
\hline Not strong & $21(148)$ & $23(14)$ & $22(24)$ \\
\hline None/absent & $18(122)$ & $31(19)$ & $24(27)$ \\
\hline Missing data & $1(5)$ & $6(4)$ & $2(2)$ \\
\hline Mean age (years) & 46 & 39 & 48 \\
\hline
\end{tabular}

tions were more likely to report high numbers of sexual concerns.

Employed African American women were more likely to report a high number sexual concerns. In contrast, unemployed Asian American and white women were more likely to report a high number of sexual concerns. Whereas white women with some college experience reported a high number of sexual concerns, African American and Asian American women with at most a high school diploma were more likely to report this. White, African American, and Asian American women in the lowest income category tended to report a high number of sexual concerns.

\section{Predictors of High Number of Sexual Concerns for Each Racial/Ethnic Group}

To assess demographic characteristics as predictors of a high number of sexual concerns within each racial/ethnic group, a series of logistic regression models were determined. We removed lifetime history of sexual coercion and physical/emotional abuse from the number of sexual concerns to control for their role in the prediction of a high number of sexual concerns. The referent groups for demographic characteristics were: age $\leq 45$, income $\leq \$ 25,000$, education $\leq$ high school, religion $=$ none/absent, relationship $=$ not married, and, for the analysis of the overall cohort, race $=$ white. "No history" of sexual coercion or physical/ emotional abuse was referent group for these 2 concerns as predictors, respectively.

A history of sexual coercion in the logistic regression models was a strong predictor of a high number of sexual concerns for the entire cohort and for each racial group. For the overall cohort and for African American women, older women and women in the higher income categories were significantly less likely to report a high number of sexual concerns. In contrast, for the overall 
Table 2. Prevalence and Comparison of Sexual Concerns among African American, Asian American, and White Women

\begin{tabular}{|c|c|c|c|}
\hline Sexual Concerns & $\begin{array}{l}\text { White Women } \\
\mathrm{N}=704 \\
\%\end{array}$ & $\begin{array}{c}\text { African American Women } \\
\mathrm{N}=66 \\
\%(\mathrm{POR})\end{array}$ & $\begin{array}{c}\text { Asian Women } \\
\mathrm{N}=111 \\
\% \text { (POR) }\end{array}$ \\
\hline Lack of interest in sex & 89 & $84(0.52)^{*}$ & $72(0.56)^{\dagger}$ \\
\hline Difficulty having orgasm & 87 & $79(0.61)^{*}$ & $72(0.42)^{\ddagger}$ \\
\hline Vaginal lubrication & 76 & $63(0.45)^{\dagger}$ & $74(0.82)$ \\
\hline Lack sex appeal & 72 & $62(0.69)$ & $47(0.39)^{\ddagger}$ \\
\hline Dyspareunia & 72 & $77(0.86)$ & $69(0.91)$ \\
\hline Unsatisfied sexual needs & 69 & $73(1.13)$ & $54(0.45)^{\ddagger}$ \\
\hline Need sex information & 65 & $709(1.25)$ & $55(0.62)^{*}$ \\
\hline Desires different than partners & 62 & $53(0.77)$ & $51(0.75)$ \\
\hline Contraception, family planning, fertility & 62 & $73(1.51)$ & $48(0.64)^{*}$ \\
\hline Inability to have orgasm & 61 & $60(0.69)$ & $61(0.52)^{\dagger}$ \\
\hline HIV/AIDS & 52 & $76(3.54)^{\S}$ & $54(1.57)^{\dagger}$ \\
\hline Safe sex/sexually transmitted diseases & 52 & $68(3.79)^{\S}$ & $51(1.67)^{\dagger}$ \\
\hline Partner sexual difficulties & 49 & $41(0.89)$ & $41(0.58)^{\dagger}$ \\
\hline Difficulty inserting penis & 48 & $44(1.11)$ & $56(1.46)^{*}$ \\
\hline Thinking too much about sex & 39 & $44(1.88)^{\dagger}$ & $37(0.94)$ \\
\hline Adult sexual coercion & 36 & $46(1.92)^{\dagger}$ & $21(0.72)$ \\
\hline Adult emotional/physical abuse & 36 & $32(1.06)$ & $22(0.43)^{\dagger}$ \\
\hline Childhood emotional/physical abuse & 34 & $36(1.02)$ & $19(0.47)^{\dagger}$ \\
\hline Want to have/have had an affair & 34 & $52(2.41)^{\dagger}$ & $21(0.80)$ \\
\hline Sexual aversion & 33 & $32(1.49)$ & $34(1.78)^{*}$ \\
\hline Hard to control sexual urges & 30 & $32(1.39)$ & $25(1.09)$ \\
\hline Sexual orientation & 25 & $28(1.54)$ & $29(1.71)$ \\
\hline Sexual interest in women & 20 & $23(1.53)$ & $20(0.87)$ \\
\hline Childhood sexual coercion & 17 & $20(1.27)$ & $12(0.61)$ \\
\hline Wish to be opposite sex & 16 & $14(1.90)$ & $15(1.09)$ \\
\hline Sexually abusive towards others & 15 & $4(5.44)$ & $8(9.76)^{*}$ \\
\hline
\end{tabular}

Kruskal Wallis test $\chi^{2}=0.412, d f=2, P=.814$ to compare relative rank of sexual concerns among the 3 racial/ethnic groups. POR, Prevalence odds ratio after controlling for demographic variables age, marital status, religion, income, and education: ${ }^{*} 0.1 \leq P \leq .05$, ${ }^{\dagger} P \leq .05,{ }^{\ddagger} P \leq .01,{ }^{\S} P \leq .001$, of African American and Asian American compared with White women.

cohort and for white and Asian American women, those with education beyond high school were significantly more likely to report a high number of sexual concerns (Table 3).

A history of physical/emotional abuse in the logistic regression model was only significantly predictive of a high number of sexual concerns for white women. Demographic characteristics had a similar pattern of prediction as those in the models with a history of sexual coercion (Table 4).

\section{Discussion}

This is the first study to compare specific sexual concerns of a combined cohort of African American, Asian American, and white women. Although the relative ranking of sexual concerns and perhaps the importance was similar across these racial/eth- nic groups, compared with white women, Asian American and African American women reported significant differences regarding certain sexual concerns. The demographic correlates of sexual concerns also differed across these racial/ethnic groups. This study highlights the fact that regardless of the racial or ethnic background, women report a high prevalence of sexual concerns that could potentially have a significant impact on their overall health and well-being. The significant difference in the prevalence of certain sexual concerns between white women and the other racial/ethnic groups suggests that some concerns may have more health importance for some racial/ethnic groups than others. Thus, health care providers should avoid generalizing women's sexual concerns across racial/ethnic groups. In addition, certain sociode- 
Table 3. Predictors of High Number of Sexual Concerns among White, African American, and Asian American Women with Sexual Coercion in Logistic Equation*

\begin{tabular}{|c|c|c|c|c|}
\hline Characteristic & $\begin{array}{c}\text { Overall OR } \\
(95 \% \mathrm{CI})\end{array}$ & $\begin{array}{l}\text { White OR } \\
(95 \% \mathrm{CI})\end{array}$ & $\begin{array}{c}\text { African American OR } \\
(95 \% \mathrm{CI})\end{array}$ & $\begin{array}{c}\text { Asian American OR } \\
(95 \% \mathrm{CI})\end{array}$ \\
\hline \multicolumn{5}{|l|}{ Sexual Coercion } \\
\hline No & 1 & 1 & 1 & 1 \\
\hline Yes & $5.3(3,8,7.4)$ & $5.7(4.0,8.2)$ & $8.9(1.2,66.4)$ & $5.9(1.5,23.0)$ \\
\hline \multicolumn{5}{|l|}{ Age } \\
\hline$\leq 45$ years & 1 & & 1 & \\
\hline$>45$ years & $0.7(0.5,0.99)$ & & $0.01(0.0,0.5)$ & \\
\hline \multicolumn{5}{|l|}{ Income } \\
\hline$\leq \$ 25,000$ & 1 & & 1 & \\
\hline$\$ 25,000$ to $\leq 40,000$ & $0.6(0.4,0.96)$ & & $0.05(0.004,0.5)$ & \\
\hline$>\$ 40,000$ & $0.7(0.4,1.1)$ & & & \\
\hline \multicolumn{5}{|l|}{ Education } \\
\hline$\leq$ High school & 1 & 1 & & 1 \\
\hline Some college & $1.9(1.3,2.8)$ & $1.7(1.1,2.7)$ & & $6.6(1.6,27.3)$ \\
\hline$\geq$ College & $2.1(1.3,3.3)$ & $1.7(1.0,2,8)$ & & $25.6(3.2,201,865)$ \\
\hline
\end{tabular}

* The referent groups for demographic characteristics were: age $\leq 45$; income $\leq \$ 25,000$; education $\leq$ high school, religion $=$ none/absent; relationship = not married; and, for the analysis of the overall cohort, race = white. "No history" of sexual coercion was referent group for this concern. Only statistically significant predictors are included in the table.

mographic characteristics were significantly associated with a high prevalence of sexual concerns, but the associations varied according to racial/ethnic group.

African American and Asian American women reported proportionately higher prevalence of concerns regarding HIV/AIDS and safe sex/sexually transmitted diseases. This group of women might be considered low risk in that a high percentage is married, is employed, possesses at least a high school education, and has a regular source of free medical care. This finding could have public health significance given that even seemingly low risk women may consider themselves at a higher risk for sexually transmitted disease, especially HIV/AIDS. Awareness among health care providers of this heightened concern among African American and Asian American women could assist these women to acquire the means to deal with this concern through education and access to methods to protect themselves.

We did find that for all participants, and after controlling for certain sociodemographic characteristics, a history of sexual coercion was signifi-

Table 4. Predictors of High Number of Sexual Concerns among White, African American, and Asian American Women with Physical/Emotion Abuse in Logistic Analysis*

\begin{tabular}{|c|c|c|c|c|}
\hline Characteristic & $\begin{array}{c}\text { Overall OR } \\
\text { (95\% CI) }\end{array}$ & $\begin{array}{l}\text { Caucasian OR } \\
(95 \% \mathrm{CI})\end{array}$ & $\begin{array}{c}\text { African American OR } \\
(95 \% \mathrm{CI})\end{array}$ & $\begin{array}{c}\text { Asian American OR } \\
(95 \% \mathrm{CI})\end{array}$ \\
\hline \multicolumn{5}{|c|}{ Physical/Emotional Abuse } \\
\hline No & 1 & 1 & & \\
\hline Yes & $2.4(1.7,3.2)$ & $2.5(1.8,3.5)$ & & \\
\hline \multicolumn{5}{|l|}{ Age } \\
\hline$\leq 45$ years & 1 & & 1 & \\
\hline$>45$ years & $0.7(0.5,0.9)$ & & $0.06(0.003,1.0)$ & \\
\hline \multicolumn{5}{|l|}{ Income } \\
\hline$\leq \$ 25,000$ & 1 & & 1 & \\
\hline$\$ 25,000$ to $\leq 40,000$ & $0.6(0.4,0.8)$ & & $0.06(0.007,0.5)$ & \\
\hline$>\$ 40,000$ & $0.6(0.4,0.9)$ & & & \\
\hline \multicolumn{5}{|l|}{ Education } \\
\hline$\leq$ High school & 1 & 1 & & 1 \\
\hline Some college & $1.7(1.2,2.5)$ & $1.5(1.05,2.4)$ & & $6.7(1.6,28.2)$ \\
\hline$\geq$ College & $1.9(1.9,2.9)$ & & & $20.3(2.5,166.1)$ \\
\hline
\end{tabular}

* The referent groups for demographic characteristics were: age $\leq 45$; income $\leq \$ 25,000$; education $\leq$ high school, religion $=$ none/absent; relationship = not married; and, for the analysis of the overall cohort, race = white. "No history" of physical/emotional abuse was the referent group for this concern. Only statistically significant predictors are included in the table. 
cantly associated with a high prevalence of sexual concerns across the racial/ethnic groups, whereas a history of physical/emotional abuse was associated with a high prevalence of sexual concerns only for white women. This finding is consistent with other studies that a history of emotional/physical abuse and sexual abuse can have a pervasive effect on health regardless of whether the outcome of interest is sexual health, general health, or the utilization of health services. ${ }^{3-7}$ However, the effects of each of these types of abuse may vary across racial/ethnic groups.

This study has several limitations and strengths. Our study reports the sexual concerns and correlates of those concerns among 3 racial/ethnic groups of women who could be considered a special population given their connection to the US military through marriage and/or employment. There is great cultural diversity among Asian American women that we could not delineate and explore the differences in sexual concerns across the cultural groups. Thus, our study's external validity is limited. The low sample size of the African American and Asian American women limited the study's statistical power. Although the questionnaire's psychometric properties have not been determined or assessed across several populations of women from diverse backgrounds, the face, content, and construct validity and the internal consistency are strengths.

Our findings have relevance for clinical practice and public health. Women from different racial and ethnic backgrounds report a high prevalence of sexual concerns and, at least for our sample, the relative importance of their sexual concerns is similar. However, health care providers should not make generalizations about specific sexual concerns of women from different racial or ethnic backgrounds or within racial/ethnic groups. A history of abuse and especially sexual coercion should be explored in women who report a high level of sexual concerns. Safe-sex concerns should be explored for women who perceive an increased risk for sexually transmitted diseases regardless of their socioeconomic status and access to health care services. Sexual health should be integrated into the overall health care of women, and clinicians must explore the sexual concerns of women and how they relate to women's overall well being.

\section{References}

1. Nusbaum MR, Gamble G, Skinner B, Heiman J. The high prevalence of sexual concerns among women seeking routine gynecological care. J Fam Pract 2000;49:229-32.

2. Laumann EO, Paik A, Rosen RC. Sexual dysfunction in the United States: prevalence and predictors. JAMA 1999;28:537-44.

3. Felitti VJ, Anda RF, Nordenberg D. Relationship of childhood abuse and household dysfunction to many of the leading causes of death in adults: the adverse childhood experiences (ACE) study. Am J Prev Med 1998;14:245-58.

4. Fleming J, Mullen PE, Sibthorpe B, Bammer G. The long-term impact of childhood sexual abuse in Australian women. Child Abuse Negl 1999;23:145-59.

5. Mullen PE, Romans-Clarkson SE, Walton VA, Herbison GP. Impact of sexual and physical abuse on women's mental health. Lancet 1988;1:841-45.

6. Plichta S. The effects of woman abuse on health care utilization and health status: a literature review. Womens Health Issues 1992;2:154-63.

7. Ulrich YC, Cain KC, Sugg NK, et al. Medical care utilization patterns in women with diagnosed domestic violence. Am J Prev Med 2003;24:9-15. 